\title{
Urgences
}

\section{Jean-Marc Cormier, Westernité, Saint-Gabriel de Rimouski, Les Éditions Passages, 1981.}

\section{Michelle Dubois}

Numéro 4, 2e trimestre 1982

URI : https://id.erudit.org/iderudit/025068ar

DOI : https://doi.org/10.7202/025068ar

Aller au sommaire du numéro

Éditeur(s)

Urgences

ISSN

0226-9554 (imprimé)

1927-3924 (numérique)

Découvrir la revue

Citer ce compte rendu

Dubois, M. (1982). Compte rendu de [Jean-Marc Cormier, Westernité,

Saint-Gabriel de Rimouski, Les Éditions Passages, 1981.] Urgences, (4), 91-94.

https://doi.org/10.7202/025068ar d'utilisation que vous pouvez consulter en ligne.

https://apropos.erudit.org/fr/usagers/politique-dutilisation/ 
Les impressions de lecture que la chûte du conte suggère vont de la force de l'humaine solidarité jusqu'à l'amour des bêtes en passant par le goût de l'aventure. Malgré ses maladresses langagières, OÜ EST LE TROU DU ROCHER PERCÉ? soulève I'intérêt par l'originalité de la scène-argument et par le fait du déroulement de I'histoire dans notre région. II faut par ailleurs regretter que l'éditeur n'ait consenti davantage d'efforts pour rendre attrayant le livre-objet au niveau de la couverture, du format et des couleurs.

Pour être plus complet, ce commentaire aurait pu comprendre quelques réactions d'enfants lecteurs... mais ce n'est pas la première fois que nous faisons à nos enfants le coup du train électrique...

Gilbert Dupuis

(1) OU EST LE TROU DU ROCHER PERCÉ?, Roselyne GrandMaison. Illustrations: I'auteur et Michel Cayouette. Editions Naaman, collection Jeunesse, 32 pages brochées, Sherbrooke, 1981.

WESTERNITÉ, Jean-Marc Cormier, Les Éditions Passages, 1981.

"La robine littéraire" qui ouvre le recueil de poèmes de JeanMarc Cormier constitue une prise de position sans équivoque:

"je suis...

le robineux qui fouille

dans les poubelles de l'humanité

et que la beauté des déchets fait rêver" (p. 9)

Ces quelques vers révèlent les deux principaux aspects de la thématique du recueil: le monde corrompu, défiguré et réducteur d'esprit dans lequel chaque être humain cherche sa lumière, son unité, et en même temps, la fonction du poète qui est de crier cette quête inouïe de bonheur et d'amour qui s'accomplit dans la nuit et la boue. 


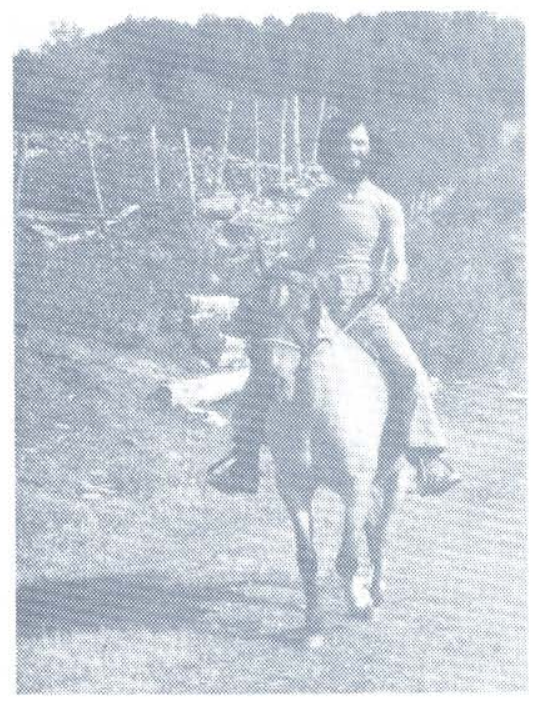

Le premier poème contient donc une justification et un engagement: I'état actuel de l'humanité justifie la poésie, et le poète existe pour fracturer "les membres du verbe / pour tenter de lui faire échapper un cri" (p. 10). S'il use d'une "écriture mal engueulée qui sape à table / faisant de grands bruits de gueule", s'il donne "de grandes claques plates / sur la surface de l'eau glauque $/(\ldots) /$ afin qu'elle saute à la face des gens" (p. 12), c'est que le poète sait que seul un réveil brutal des consciences permettra la reprise en nos mains de notre vie et de notre destinée.

Après une telle ouverture, les poèmes-chansons de "Tel quel" qui constituent la deuxième partie du recueil, ne surprennent guère. Jean-Marc Cormier y dénonce l'un après l'autre les vices de notre société: règne de l'argent, corruption, guerre, désoeuvrement, solitude, manque d'amour, etc., tout cela bien enrobé dans l'inconscience cultivée par les pouvoirs dominants. Dans la plupart de ces textes, à part des images qui savent nous arracher un sursaut ('"je n'suis qu'un effort / pour voir dans le noir / je n'suis qu'une luciole..." (p. 26), L'Exhibitionniste, et "dans sa jupe fatale / a brodé des balles / ramassées que'que 
part / au Vietnam du Nord" (L'Amérique à pitons, p. 19), la rime, le retour des refrains, le rythme court des vers destinés à la chanson finissent par alléger les textes, par les rendre "consommables" et digestibles quand il ne provoquent pas le sourire désabusé de celui qui en a vu d'autres. Non, ici le cri manque de souffle, de présence, de cette présence que l'auteur-interprète de chansons peut avoir sur une scène quand c'est avec tout son corps qu'il projette vers son public le poids et la densité de sa parole.

Ce souffle qu'on attendait, le coup de gueule que nous promettait "La robine littéraire", ce sont surtout les poèmes de la troisième partie du recueil qui nous l'apportent. Dans cette section intitulée "Westernité" sont souvent reliés inextricablement la noirceur et la lumière, le cauchemar et le rêve d'amour, le silence et le cri. Tout cela porté par le désir de dire, d'écrire et de transformer ainsi le monde pour pouvoir "entrer dans la lumière à plein corps, en échappant un grand cri / de mes propres terreurs pour une fois libéré..." (ABDMD DPCG ADLB, p..52). Ainsi, c'est quand l'auteur raconte le drame de l'homme qui se promène avec des mots "coupés en deux / qui ne veulent plus dire / que la moitié du sens de chaque chose" (Visage avoir deux faces, p. 29), c'est quand il se présente lui-même aux prises avec les mots comme avec "des couteaux à deux tranchants" (Le Bal des mots, p. 54), qu'il réussit à trouver en lui-même cet accent particulier qui fait qu'un poème n'est pas une chanson. Naissent alors des paroles de tendresse et d'amour comme dans "Parler longtemps", des cris de révolte, de haine ou de mépris comme dans "Les camisoles de broche", les chants d'espoir de "Tout doucement" et "St-Laurent-Beaubien". Tous ces poèmes où il y a un "je" conscient de la mort et tourné vers la vie, où le "je" c'est le poète aux prises avec la nécessité de "mener le verbe à sa plus parfaite réalisation / lui donner chair entre les dents" (p. 82), qui assume à sa façon l'humanité déchirée, réalisent mieux, à mon avis, cette poésie "qui crispe la conscience un moment / avant de la faire éclater" (p. 9).

Quand Jean-Marc Cormier, dans "Écrire" rêve d"'un homme / un seul / mais qui vivrait tous les drames / et jouerait toutes les comédies / parlant en même temps de tous les senti- 
ments" (p. 86), il nous redit à sa façon l'exigence pour le poète de faire place au monde en lui mais sans se cacher derrière lui. Le "je" qui s'accomplit alors "dans toute sa misérable splendeur", en adhérant à sa vérité, nous appelle à découvrir et à vivre la nôtre.

Michelle Dubois 